\title{
Myocardial infarction in childhood: clinical analysis of 17 cases and medium term follow up of survivors
}

\author{
David S Celermajer, Gary F Sholler, Robert Howman-Giles, John M Celermajer
}

\begin{abstract}
Between 1979 and 198917 patients aged two months to 12 years with acute myocardial infarction of any cause (other than after cardiac surgery) were seen at a children's hospital. Eight died from three days to three years after diagnosis (overall mortality $47 \%$ ). The nine survivors, now aged 2-17 years, have been followed for one to 10 years (mean follow up five years) after infarction. The commonest causes of myocardial infarction in this series were anomalous origin of left coronary artery from the pulmonary artery (six patients $(35 \%)$ ) and Kawasaki disease (five patients $(27 \%)$ ). The main symptoms of acute myocardial infarction were dyspnoea, vomiting, and difficulty feeding. Diagnosis was made in all patients by electrocardiography and confirmed by echocardiography, cardiac catheterisation, or at operation. All survivors were symptom free with excellent exercise capacity. The left ventricular ejection fraction in survivors ranged from $21 \%$ to $66 \%$, and only one child was on regular cardiac medications. There were no cases of late sudden death. Twenty four hour Holter monitoring performed on survivors was normal (seven) or showed minor abnormalities only (one), suggesting that serious arrhythmia is rare after paediatric myocardial infarction.

Myocardial infarction in children had a high early mortality; however, the incidence of serious arrhythmia was low in the survivors, who had a good exercise tolerance even when the left ventricular ejection fraction was low.
\end{abstract}

The Adolph Basser Institute of Cardiology, The Children's Hospital, Camperdown, Sydney, Australia D S Celermajer G F Sholler R Howman-Giles J M Celermajer Dr John M Celermajer died on 13 March 1990

Correspondence to Dr Gary F Sholler, Adolph Basser Institute of Cardiology, The Children's Hospital, Camperdown 2050 Sydney, Australia.

Accepted for publication 14 January 1991
Myocardial infarction is rare in infancy and childhood. ${ }^{12}$ There have been several reports of myocardial infarction complicating Kawasaki disease, ${ }^{3-6}$ anomalous coronary arteries, ${ }^{7}$ coronary embolus, ${ }^{8}$ myocarditis, ${ }^{910}$ chest trauma, ${ }^{11} 12$ and various rare paediatric diseases. ${ }^{13-15}$ But there has been no reported systematic follow up of a considerable number of children with non-operative myocardial infarction from all causes.

We therefore collected clinical data and systematically investigated patients with proven myocardial infarction from our hospital to examine the clinical profile of those affected and evaluate the state of survivors.

\section{Patients and methods}

We reviewed the records of all children with typical electrocardiographic findings of acute myocardial infarction seen at the Royal Alexandra Children's Hospital, Sydney, between February 1979 and February 1989.

Records of all necropsies carried out at the hospital over that time and echocardiography or operative reports of high risk conditions (that is Kawasaki disease and anomalous left coronary artery) were also examined to detect any additional cases, but none was found.

Survivors underwent a series of noninvasive investigations between July and September 1989. Twelve lead electrocardiography, cross sectional, and Doppler echocardiography with particular attention to left ventricular wall motion and left ventricular fractional shortening, and 24 hour Holter monitoring (Hewlett Packard 43400B patient analyser) were carried out by standard techniques. ${ }^{1617}$ Bicycle or treadmill exercise testing was performed by incremental increases in workload in the standard manner, as described elsewhere. ${ }^{18-20}$ Predicted values for pulse and blood pressure response, and for maximum workload for age, size, and sex were obtained from standard references. ${ }^{21} 22$

Stress thallium-201 myocardial scans were performed after an intravenous infusion of dipyridamole $(0.56 \mathrm{mg} / \mathrm{kg})$ over four minutes. $^{2324}$ Thallium-201 citrate adjusted for body weight $(1.75 \mathrm{mBq} / \mathrm{kg})$ with a minimum dose of $15 \mathrm{mBq}$ was administered at eight minutes. Planar imaging in the anterior, left anterior oblique $40^{\circ}$; left anterior oblique $60^{\circ}$; and left lateral positions was performed with a Starcom 400 AT gamma camera. Images were taken at five minutes and at three hours after the injection of thallium-201. Computer enhancement of images and circumferential count profiles were performed. Images were divided into five equal ventricular segments as previously described. ${ }^{25}$

Radionuclide gated heart pool scans were performed at rest by electrocardiographically synchronised blood pool imaging of red blood cells labelled in vivo with technetium-99m. ${ }^{26}$ Images were acquired in the anterior, modified left anterior oblique, and left lateral positions. We used a small field of view 300 A General Electric gamma camera fitted with high resolution $30^{\circ}$ slant hole collimator that was interfaced with a DEC gamma 11 (PDP-11/34) computer system. Images were obtained as 24 frames in a $64 \times 64$ matrix and were analysed for evidence of regional wall motion abnor- 
Table 1 Data on 17 patients with paediatric myocardial infarction

\begin{tabular}{lllllll}
\hline Case & Sex & Age at $M I$ & Diagnosis & $\begin{array}{c}\text { Period of } \\
\text { follow-up }\end{array}$ & Operation/age & Outcome \\
\hline 1 & $\mathrm{M}$ & $3 \mathrm{mnth}$ & ALCA & $10 \frac{1}{2} \mathrm{yr}$ & ALCA repair/5 yr & Alive \\
2 & $\mathrm{~F}$ & $4 \mathrm{mnth}$ & ALCA & $2 \frac{1}{2} \mathrm{yr}$ & ALCA repair/5 mnth & Alive \\
3 & $\mathrm{~F}$ & $3 \mathrm{mnth}$ & ALCA & $7 \frac{1}{2} \mathrm{yr}$ & ALCA repair/9 mnth & Alive \\
4 & $\mathrm{M}$ & $10 \mathrm{mnth}$ & KD & $2 \mathrm{yr}$ & - & Alive \\
5 & $\mathrm{~F}$ & $14 \mathrm{mnth}$ & KD & $4 \frac{1}{2} \mathrm{yr}$ & - & Alive \\
6 & $\mathrm{M}$ & $18 \mathrm{mnth}$ & KD & $3 \mathrm{yr}$ & Alive \\
7 & $\mathrm{M}$ & $6 \mathrm{mnth}$ & KD & $4 \mathrm{yr}$ & Alive \\
8 & $\mathrm{M}$ & $9 \mathrm{yr}$ & Trauma & $8 \mathrm{yr}$ & Alive \\
9 & $\mathrm{~F}$ & $12 \mathrm{yr}$ & Myo & $1 \mathrm{yr}$ & Alive \\
10 & $\mathrm{~F}$ & $10 \mathrm{mnth}$ & Myo & $16 \mathrm{mnth}$ & ALCA repair/8 mnth & Dead \\
11 & $\mathrm{~F}$ & $4 \mathrm{mnth}$ & ALCA & $4 \mathrm{mnth}$ & - & Dead \\
12 & $\mathrm{M}$ & $3 \mathrm{mnth}$ & Embolus & $6 \mathrm{mnth}$ & - & Dead \\
13 & $\mathrm{~F}$ & $6 \mathrm{mnth}$ & ALCA & $1 \mathrm{mnth}$ & - & Dead \\
14 & $\mathrm{~F}$ & $2 \mathrm{mnth}$ & Fibrosis & $2 \mathrm{mnth}$ & ALCA repair/5 mnth & Dead \\
15 & $\mathrm{~F}$ & $4 \mathrm{mnth}$ & ALCA & $3 \mathrm{yr}$ & - & Dead \\
16 & $\mathrm{~F}$ & $2 \mathrm{yr}$ & KD & $3 \mathrm{days}$ & - & Dead \\
17 & $\mathrm{~F}$ & $8 \mathrm{yr}$ & H/T & 3 days & - & \\
\hline
\end{tabular}

ALCA, anomalous origin of left coronary artery; Embolus, coronary embolus; Fibrosis, internal fibrosis of coronary artery; $\mathrm{H} / \mathrm{T}$, hypertension with renal failure; KD, Kawasaki disease; LVAn, left ventricular aneurysmectomy; MI, myocardial infarction; Myo, myocarditis, probable coronary embolus; Trauma, blunt chest trauma.

malities and for quantification of ejection fraction. ${ }^{27}$

\section{Results}

We identified 17 children (six boys, 11 girls) with typical electrocardiographic features of myocardial infarction at our hospital between February 1979 and February 1989 (table 1) Those with myocardial infarction after cardiac surgery were excluded.

Age at diagnosis ranged from two months to 12 years, with 14 patients $(82 \%)$ being diagnosed at the age of 2 years or younger. Twelve patients $(71 \%)$ presented with dyspnoea as the primary symptom, accompanied by vomiting or poor feeding. Two patients presented with out-of-hospital cardiac arrest (one later died), one had features of Kawasaki disease and an abnormal electrocardiogram, and two older children presented with chest pain.

The myocardial infarction was in the territory of the left coronary system in 15 of the 17 children, including the eight who died, and in the area supplied by the right coronary artery in two.

Table 2 shows the causes of myocardial infarction in this group of children. Anomalous left coronary artery arising from the pulmonary artery $(35 \%)$ and Kawasaki disease (29\%) accounted for most cases.

\section{SURVIVORS}

Nine patients aged from two months to 12 years at the time of myocardial infarction were alive 5 (3) (range 1-10) years after infarction. All were symptom free and were active participants in appropriate pastimes for their age. One patient (case 6) was taking cardiac medication (capto- pril, digoxin, and frusemide). Three patients were taking aspirin after Kawasaki disease.

Four children had open heart surgery after diagnosis. Three had surgical reimplantation of an anomalous left coronary artery to aorta. One patient with congestive cardiac failure refractory to medical treatment had resection of left ventricular aneurysm and repair of mitral valve three years after a post-traumatic coronary occlusion with infarction.

Table 3 summarises the investigations. Chest $x$ rays were normal in two patients (patients 4 and 9) and showed mild cardiac enlargement in the other seven children. No $x$ rays showed evidence of pulmonary venous congestion or interstitial oedema. Electrocardiography showed a pattern typical of past infarction in all the children.

The size of the infarct was assessed by dipyridamole thallium-201 myocardial scintigraphy in seven patients (one patient lives in rural New South Wales and was not able to have a thallium scan and one refused the test). All showed fixed perfusion defects of varying size consistent with scar tissue from past myocardial infarction.

Left ventricular function was assessed in all survivors by echocardiography or radionuclide gated heart pool scans or both. Left ventricular ejection fractions ranged from $21 \%$ to $66 \%$, with most having ejection fractions $<50 \%$. Three children had mild mitral regurgitation. Wall motion abnormalities were detected and were concordant on echocardiograms and thallium scans. The echocardiogram did not show apical dyskinesis well. Mural thrombus was not detected in any patient.

Exercise capacity was assessed by formal

Table 2 Causes of childhood myocardial infarction

\begin{tabular}{llll}
\hline Disease & Survivors & Non-survivors & Total (\%) \\
\hline Anomalous origin of left coronary artery from pulmonary artery & 3 & 3 & $6(35)$ \\
Kawasaki disease & 4 & 1 & $5(29)$ \\
Myocarditis-probable coronary embolus & 1 & 1 & $2(12)$ \\
Blunt chest trauma & 1 & 1 & $1(6)$ \\
Hypertension & - & 1 & $1(6)$ \\
Intimal fibrosis of coronary artery & - & 1 & $1(6)$ \\
Absent, thrombosed, or embolised left coronary artery & & $1(6)$ \\
\hline
\end{tabular}


Table 3 Follow up investigation in survivors of paediatric myocardial infarction

\begin{tabular}{|c|c|c|c|c|c|}
\hline Case & $\begin{array}{l}\text { Age at } \\
\text { follow up }\end{array}$ & Thallium scan & $\begin{array}{l}\text { Gated } \\
\text { LVEF (\%) }\end{array}$ & $\begin{array}{l}\text { Heart pool scan } \\
\text { wall motion }\end{array}$ & $\begin{array}{l}\text { Holter } \\
\text { monitoring }\end{array}$ \\
\hline $\begin{array}{l}1 \\
2 \\
3\end{array}$ & $\begin{array}{l}10 \frac{1}{2} \text { yr } \\
2 \text { yr } 10 \text { mnth } \\
7 \text { yr } 9 \text { mnth }\end{array}$ & $\begin{array}{l}\text { Fixed defect in posteroinferior wall } \\
\text { Thinning of anteroseptal area }\end{array}$ & $\begin{array}{l}64 \\
66 \\
\end{array}$ & $\begin{array}{l}\text { Area of hypokinesis in high posterior wall } \\
\text { Normal }\end{array}$ & $\begin{array}{l}\text { Normal } \\
\text { Normal } \\
-\end{array}$ \\
\hline 4 & 2 yr 10 mnth & Mild fixed apical defect & 52 & Moderate apical hypokinesis & Normal \\
\hline 5 & $6 \mathrm{yr}$ & Fixed defect in anteroseptal wall & 41 & Moderate anteroseptal hypokinesis & Normal \\
\hline 6 & $4 \frac{1}{2} \mathrm{yr}$ & Fixed anteroseptal and lateral wall defects & 23 & Anteroseptal and lateral wall akinesis & Normal \\
\hline 7 & $4 \frac{1}{2} \mathrm{yr}$ & Fixed anteroseptal defect & 21 & Anteroseptal hypokinesis; apical dyskinesis & $\begin{array}{l}\text { Run of } 4 \text { VEs at } 90 / \mathrm{min} \text {; } \\
\text { otherwise normal }\end{array}$ \\
\hline $\begin{array}{l}8 \\
9\end{array}$ & $\begin{array}{l}17 \mathrm{yr} \\
13 \mathrm{yr}\end{array}$ & $\overline{\text { Fixed anteroseptal defect }}$ & $\begin{array}{l}47 \\
31\end{array}$ & $\begin{array}{l}\text { Anterior wall hypokinesis } \\
\text { Anteroapical akinesis }\end{array}$ & $\begin{array}{l}\text { Normal } \\
\text { Normal }\end{array}$ \\
\hline
\end{tabular}

LVEF, left ventricular ejection fraction; VEs, ventricular extrasystoles.

exercise stress testing (five patients), or history and direct observation (in three patients who were too young to attempt formal exercise testing and in one patient who lived too far from a suitable exercise testing facility). Exercise capacity was $\geqslant 80 \%$ of that predicted in all patients formally tested, with normal pulse and blood pressure response. None developed chest pain, dyspnoea, or electrocardiographic changes suggestive of ischaemia.

Twenty four hour Holter monitoring was performed in eight patients (but not in one who lived in rural New South Wales). This was normal in seven patients and showed minor abnormality only in one (four consecutive ventricular extrasystoles at a rate of 90 beats per minute but otherwise normal). There were no episodes of palpitation, syncope, or out-ofhospital cardiac arrest in any patients.

DEATHS

Eight children died. All had extensive infarction of the left ventricle demonstrated by left ventriculography (two patients) or necropsy (six patients). Two children had undergone surgical repair for anomalous coronary artery.

Six children died within six months of diagnosis. Death was from cardiogenic shock, intractable heart failure or at the time of cardiac catheterisation (one patient) or surgery (one patient). Two children had longer survival times (16 months, three years), succumbing to intractable heart failure despite maximum medical treatment. There were no cases of late sudden death.

\section{Discussion}

Acute myocardial infarction is a rare cause of morbidity and mortality in childhood. We have identified 17 children seen at our hospital with myocardial infarction over a 10 year period. Mortality was high (47\%) and generally occurred within 6 months of diagnosis. Excellent cardiovascular fitness and an absence of serious arrhythmia were found in survivors, even in the presence of significant left ventricular dysfunction. There were no cases of sudden out-of-hospital death. In this series, however, the number of survivors was small and there was a variety of diagnostic categories. It is therefore difficult to make authoritative conclusions about the late incidence of arrhythmia and sudden death after myocardial infarction in childhood.
There has been little information on paediatric myocardial infarction. Atherosclerosis, the most common predisposing lesion in adult myocardial infarction, is exceedingly rare in the paediatric population. ${ }^{28}$ Chest pain, the most frequent symptom of myocardial ischaemia and infarction in adults, cannot be reported by neonates or infants. Therefore not only is the prevalence of myocardial infarction in children low but clinical detection of the condition may be difficult.

The diagnosis of myocardial infarction in children was made by electrocardiography supplemented by echocardiography and cardiac catheterisation. Electrocardiography is not $100 \%$ sensitive for myocardial infarction, ${ }^{29} 30$ and so we may have underestimated the number of children with myocardial infarction.

There are many reported causes of myocardial infarction in childhood. In our series, anomalous origin of left coronary artery from the pulmonary artery and Kawasaki disease were the commonest causes. Myocarditis has been reported to cause both segmental cardiac necrosis mimicking myocardial infarction ${ }^{31}$ and coronary occlusion with "true" myocardial infarction. The presumed mechanism of the latter is either coronary arteritis with thrombosis or coronary embolism from left ventricular thrombus, which we believe was the mechanism in our two patients. Blunt chest trauma has been reported to cause myocardial infarction secondary to traumatic coronary occlusion. ${ }^{1132}$ Other causes include intimal irregularities with in situ coronary thrombosis ${ }^{33}$ in utero paradoxical embolus, ${ }^{8}$ severe cyanosis, ${ }^{14}$ perinatal asphyxia, ${ }^{34}{ }^{35}$ and generalised arterial calcification of infancy. ${ }^{15}$

Mortality was high (47\%) in our series. Late diagnosis in children because symptoms are not reported means that appropriate treatment is often not given immediately after acute myocardial infarction. ${ }^{36}$ Anomalous origin of left coronary artery presenting in infancy has a high mortality in all series, ${ }^{37-39}$ because ischaemia or infarction affects a large proportion of left ventricular muscle. The high incidence of severe cardiac failure in our patients reflects the generally large infarcts. This was confirmed at necropsy in six of the eight non-survivors.

In 1969, Imrich Bor analysed 29 cases of childhood myocardial infarction identified from necropsy files between 1945 and $1960 .^{9}$ The average age of this patient group was five years, 
and only one of 29 patients survived more than four months after diagnosis.

Two $(12 \%)$ of our 17 cases presented with cardiac arrest, which may have been caused by early ventricular arrhythmia. This is similar to the finding of Adgey et al in adults, who found ventricular arrhythmias in $11.5 \%$ of 284 patients within 24 hours of the onset of myocardial infarction. ${ }^{40}$

There have been no series analysing long term follow up in survivors of childhood myocardial infarction. In 1986 Nakano et al identified 11 patients with myocardial infarction after Kawasaki disease, of whom two died. ${ }^{41}$ The diagnosis was made by electrocardiography and echocardiography. In 1986 Kato et al identified the clinical and laboratory features of cardiac disease in the acute phase of Kawasaki disease in 195 patients from 151 major hospitals in Japan; however, follow up data beyond the acute phase are not provided. ${ }^{42}$

We followed nine survivors of paediatric myocardial infarction from one to 10 years. Some had had large infarcts, with left ventricular ejection fractions of less than $25 \%$ and large areas of akinetic ventricular wall, whereas others had small infarcts with minimal left ventricular dilatation. The striking feature was that all nine were symptom free, only one needed cardiac medication, and all had excellent exercise capacity both on history and formal testing.

This good exercise tolerance has several explanations. Firstly, children have healthy peripheral vessels, with high compliance, low resistance, and optimal myocardial/vascular coupling. ${ }^{43}$ This may lower afterload, which has been shown to improve left ventricular remodelling and ejection fraction in adults after myocardial infarction. ${ }^{44}$ Second, the noninfarcted myocardium should be completely healthy in children. Third, respiratory efficiency and reserve provides for considerable exercise capacity in children, which would be better than respiratory reserve in adults with myocardial infarction, many of whom have smoked heavily. Fourth, evidence from survivors of anomalous left coronary artery suggested a considerable capacity for recovery of myocardial function in children after an ischaemic insult. ${ }^{45} \mathrm{~A}$ combination of these factors may account for the observed cardiovascular fitness of these children after myocardial infarction.

In contrast with adult series there were no instances of late cardiac arrest or sudden death in our series. Studies of adults who leave hospital after a first myocardial infarction suggest a five year mortality of approximately $25 \%$ with over half of these deaths being sudden, ${ }^{46} 47$ and with many occurring in the first 12 months after infarction..$^{48}$

The absence of sudden cardiac death in children after myocardial infarction in our series is difficult to explain. The young myocardium may be less prone to the development of re-entry circuits after infarction if there is less pre-existing disease of ventricular muscle. Furthermore, in infants and children good collateral blood flow in the myocardium might protect peri-infarctional ischaemic areas.
Patients with Kawasaki disease may, however, prove to have poor coronary flow reserve because of coronary artery scarring. ${ }^{49}$

In our series no children surviving myocardial infarction had frequent ventricular extrasystoles on 24 hour electrocardiogram recordings, including those with a left ventricular ejection fraction of $<40 \%$. This places them in a low risk group for late ventricular arrhythmias. In adults with myocardial infarction who survive long enough to be discharged from hospital $40-50 \%$ have frequent or multiform ventricular extrasystoles on single 24 hour electrocardiogram recordings in the months after myocardial infarction..$^{50-52}$

We reviewed data on 17 cases of nonoperative paediatric myocardial infarction over a 10 year period. Eight children died, most of them less than six months after diagnosis, and all had large left ventricular infarcts. There were no cases of sudden out-of-hospital death. Nine survivors are currently symptom free with good exercise tolerance and no or only minor abnormalities on 24 hour electrocardiogram recordings.

1 Stryker WA. Coronary occlusive disease in infants and in children. Am J Dis Child 1946;71:280-300.

2 Host NB, Hasselbalch H, Feldt-Rasmussen B. Myocardia infarction before the age of 20 is rare [Letter]. Eur $J$ Haematol 1988;41:511.

3 Yanagisawa M, Kobayashi N, Matsuya S. Myocardial infarction due to coronary thromboarteritis following acute mucocutaneous lymph node syndrome in an infant. Pediatrics 1974;54:277-81.

4 Radford DJ, Sondheimer HM, William GJ, Fowler RS. Mucocutaneous lymph node syndrome with coronary Mucocutaneous lymph node syndrome with coron

5 Kegel SM, Dorsey TJ, Rowen M, Taylor WF. Cardiac death in mucocutaneous lymph node syndrome. Am J Cardiol 1977;40:282-6.

6 Kato H, Ichinose E, Yoshioka F, et al. Fate of coronary aneurysms in Kawasaki disease: serial coronary angiography and long-term follow-up study. Am J Cardiol 1982;49:1758-66.

7 Menahem S, Venables AW. Anomalous left coronary artery from the pulmonary artery: a 15 year sample. Br Heart $J$ 1987;58:378-84.

8 Bernstein D, Finkbeiner WE, Soifer S, Teitel D. Perinatal myocardial infarction: a case report and review of the literature. Pediatr Cardiol 1986;6:313-7.

9 Bor I. Myocardial infarction and ischaemic heart disease in infants and children. Arch Dis Child 1969;44:268-81.

10 Wroblewska-Kuluzewska M, Wojcicka-Urbanska B. A case of myocardial infarction in an 11-year-old girl with of myocardial infarction in an 11-yea

11 Parmley LF, Manion C, Mattingly TW. Nonpenetrating cardiac trauma. Circulation 1958;18:371-96.

12 Jones FL Jr. Transmural myocardial necrosis after nonpenetrating cardiac trauma. Am J Cardiol 1970;26:419-22

13 Courtemanche DJ, Firth CE, Onyet J. Myocardial infarction in a child with salmonella enterocolitis. Paediatr Cardiol 1986;6:279-81.

14 de Moor MMA, Vosloo SM, Human DG. Myocardial infarction in a neonate with cyanotic congenital heart disease. Pediatr Cardiol 1986;6:219-21.

15 Sholler GF, Yu JS, Dale PM, Hawker RE, Celermajer JM, Kozlowski K. Generalised arterial calcification of infancy: Kozlowski long term survival. J Pediatr 1984;105:257-60.

16 Borow K. An integrated approach to the noninvasive assessment of left ventricular systolic and diastolic performance. In: St John Sutton M, Oldershaw P, eds. Textbook of adult In: St John Sutton M, Oldershaw $\mathrm{P}$, eds. Textbook of adult and paediatric echocardiography and Doppler.

17 Bigger JT Jr, Reiffel JA, Coromilas J. Ambulatory electrocardiography. In: Platia EV, ed. Management of cardiac trocardiography. In: Platia EV, ed. Management of cardiac

18 Godfrey S. Exercise and pulmonary function. In: Anderson RH, Macartney FJ, Shinebourne EA, Tynan M, eds. Paediatric cardiology. New York: Churchill Livingstone, 1987:395-420.

19 Cumming GR, Friesen W. Bicycle ergometer measurement of maximal oxygen uptake in children. Can J Physiol Pharmacol 1967;45:937-46.

20 Anderson SD, Godfrey S. Cardiorespiratory response to treadmill exercise in normal children. Clin Sci $1971 ; 40: 433-42$.

21 Sheffield LT. Exercise stress testing. In: Braunwald E, ed. 
Heart disease: a textbook of cardiovascular medicine. Philadelphia: WB Saunders, 1988:223-41.

22 Weber KT, Janicki JS. Cardiopulmonary exercise testing In: Weber KT, Janicki JS. Cardiopulmonary exercise testing. Philadelphia: WB Saunders, 1986:1-22.

23 Josephson MA, Brown BG, Hecht HS, Hopkins J, Pierce $C D$, Peterson RB. Noninvasive detection and localization of coronary stenosis in patients: comparison of resting dipyridamole and exercise thallium-201 myocardial perfusion imaging. Am Heart $J$ 1982;102:1008-18.

24 Leppo J, Boucher CA, Okada RD, Newell JB, Strauss HW, Pohost GM. Serial thallium-201 myocardial imaging after dipyridamole infusion: diagnostic utility in detecting coronary stenosis and relationship to regional wall motion. Circulation 1982;66:649-57.

25 Rigo P, Beck LC, Griffith LSC, et al. Influence of coronary collateral vessels on the results of thallium-201 myocardial stress imaging. Am J Cardiol 1979;44:452-62.

26 Srivastava SC, Chervu LR. Radionuclide-labelled red blood cells: current status and future prospects. Semin Nucl Med 1984;14:68-82.

27 Hutton BF, Cormack J, Fulton PR. A software package for the analysis of gated cardiac blood pool studies. Australa Phys Eng Sci Med 1982;5:128-30.

28 Neufeld HN, Blieden LC. Coronary artery disease in children. Prog Cardiol 1975;4:119-49.

29 Sullivan W, Vlodaver Z, Tuna N, et al. Correlation of electrocardographic and pathologic findings in healed myocardial infarction. Am J Cardiol 1978;2:724-32.

30 Levine HD, Phillips C. An appraisal of the newer electrocardiography: correlation in one hundred and fifty consecutive autopsied cases. $N$ Engl J Med 1951;245:833-42.

31 Tsukada K, Takemura N, Itho K, et al. Myocarditis with myocardial infarction like findings in a 3-year old girl. Jpn Circ J 1986;50:1275-9.

32 Kahn JK, Buda AJ. Long-term follow-up of coronary artery occlusion secondary to blunt chest trauma. Am Heart J 1987:113:207-10.

33 Gault MH, Usher R. Coronary thrombosis with myocardial infarction in a newborn infant: clinical electrocardiographic and post-mortem findings. $N \mathrm{Engl} J \mathrm{Med}$ 1968;263:379-8

34 Brown NJ. Myocardial infarction in the newborn [Abstract] Arch Dis Child 1974;49:494.

35 Kilbride H, Way GL, Mersenstein GB, Winfield JM. Myocardial infarction in the neonate with normal heart and coronary arteries. Am J Dis Child 1980;134:759-62.

36 Burtt DM, Pollack P, Bianco JA. Intravenous streptokinase in an infant with Kawas
37 Vouhe PR, Baillot-Vernant F, Trinquet F, et al. Anomalous left coronary artery from the pulmonary artery in infants. Which operation? When? J Thorac Cardiovasc Surg 1987;94:192-9.

38 Keith JD. The anomalous origin of the left coronary artery from the pulmonary artery. Br Heart J 1959;21:149-61.

39 Wesselhoeft H, Fawcett JS, Johnson AL. Anomalous origin of the left coronary artery from the pulmonary trunk. Circulation 1968;38:403-25.

40 Adgey AAJ, Allen JD, Geddes JS, et al. Acute phase of myocardial infarction. Lancet $1971 ; \mathbf{i i}: 501-4$

41 Nakano H, Saito A, Ueda K, Nojima K. Clinical characteristics of myocardial infarction followirg Kawasaki disease: report of 11 cases. J Pediatr 1986;108:198-203.

42 Kato H, Ichinose E, Kawasaki T. Myocardial infarction in Kawasaki disease: clinical analyses in 195 cases. J Pediat 1986;108:923-7.

43 O'Rourke M. Arterial function in health and disease. New York: Churchill Livingstone, 1982:153-70, 185-96.

44 Sharpe N, Smith H, Murphy J, Hannan S. Treatment of patients with symptomless left ventricular dysfunction patients with symptomless left ventricular dy

45 Rein AJJT, Conan SD, Parness IA, Sanders SP Regiona and global left ventricular function in infants with and global left ventricular function in infants with anomalous origin of the left coronary artery from the pulmonary trunk: preoperative and

46 Norris RM, Caughey DE, Mercer CJ, Scott PJ. Prognosis after myocardial infarction. Six year follow-up. Br Heart 1974;36:786-90

47 Kannel WB, Sorlie P, McNamara P. Prognosis after initia myocardial infarction: the Framingham study. $\mathrm{Am}$ Cardiol 1978;42:202-9.

48 Bigger JT, Heller CA, Wenger TL, Weld FM. Ris stratification after acute myocardial infarction. $A m$ Cardiol 1978;42:202-9.

49 Spevak PJ, Newburger J, Keane J, Selwyn A, Takahashi $M$. Reactivity of coronary arteries in Kawasaki syndrome: an analysis of function [Abstract]. Am J Cardiol 1987;60:640.

50 Kleiger RF, Martin TF, Miller JP, et al. Ventricula tachycardia and ventricular extrasystoles during the late tachycardia and ventricular extrasystoles during the late recovery phase of my

51 Van Durme JP, Pannier RH. Prognostic significance of ventricular dysrhythmias 1 year after myocardial infarction [Abstract]. Am J Cardiol 1976;37:178.

52 Kostis JB, Byington R, Friedman IM, et al. Prognostic significance of ventricular ectopic activity in survivors of acute myocardial infarction. $J \mathrm{Am}$ Coll Cardio 1987;10:231-42. 